\title{
Five cases of tonsillectomy and steroid pulse therapy for recurrent immunoglobulin A nephropathy after kidney transplantation
}

\author{
Yoshie Hoshino $\cdot$ Yasutomo Abe $\cdot$ Mariko Endo $\cdot$ Sachiko Wakai • \\ Hiroki Shirakawa $\cdot$ Osamu Hotta $\cdot$ Hideki Ishida $\cdot$ \\ Kazunari Tanabe $\cdot$ Ken Tsuchiya $\cdot$ Kosaku Nitta
}

Received: 24 May 2013/Accepted: 27 August 2013/Published online: 12 September 2013

(C) The Author(s) 2013. This article is published with open access at Springerlink.com

\begin{abstract}
Five cases of recurrent immunoglobulin A nephropathy (IgAN) after kidney transplantation were successfully treated by tonsillectomy and steroid pulse therapy (SPT). The clinical background and pathology in the five cases were different, but good results were obtained in all of them. In cases 1 and 2, mild recurrent IgAN developed and failed to remit after tonsillectomy alone, but a remission was achieved in both cases after SPT. In case 3, highly active recurrent IgAN with crescent lesions developed 13 years after kidney transplantation, and a remission was achieved after SPT. In case 4, renal biopsy specimens showed pathological findings of recurrent IgAN with tubulitis, and hematuria and proteinuria resolved after SPT. In case 5, the biopsy findings indicated recurrent $\operatorname{IgAN}$ with chronic rejection. Tonsillectomy was
\end{abstract}

Y. Hoshino $(\bowtie) \cdot$ K. Tsuchiya $\cdot$ K. Nitta

Department of Medicine, Kidney Center, Tokyo Women's

Medical University, 8-1 Kawada-cho, Shinjuku-ku,

Tokyo 162-8666, Japan

e-mail: yhoshino@kc.twmu.ac.jp

Y. Abe $\cdot$ M. Endo $\cdot$ S. Wakai

Department of Nephrology, Okubo Hospital, Tokyo

Metropolitan Health and Medical Treatment Corporation,

Tokyo, Japan

H. Shirakawa

Department of Transplantation, Okubo Hospital, Tokyo

Metropolitan Health and Medical Treatment Corporation,

Tokyo, Japan

O. Hotta

Hotta Osamu Clinic, Miyagi, Japan

H. Ishida $\cdot$ K. Tanabe

Department of Urology, Tokyo Women's Medical University,

Tokyo, Japan followed by resolution of the proteinuria, and a remission was achieved after SPT. In conclusion, SPT is effective in inducing a remission of recurrent IgAN when tonsillectomy alone fails.

Keywords Recurrent IgA nephropathy . Tonsillectomy $\cdot$ Steroid pulse · Kidney transplantation

\section{Introduction}

Recurrent IgA nephropathy (re-IgAN) after kidney transplantation (KT) influences graft survival but there is no established standard treatment. We report five cases of reIgAN with different characteristics, which achieved remission by tonsillectomy and steroid pulse therapy (SPT).

\section{Case reports}

The clinical characteristics of the five cases are shown in Table 1. All cases were confirmed a biopsy-proven IgAN before entering dialysis in each hospital.

Case 1

The patient was performed ABO-compatible KT at 32 years of age. IgA deposition without $\mathrm{C} 3$ was identified by 0 -h biopsy, but no active lesion was detected and it decreased by the second-year biopsy. Hematuria appeared in the fifth year, and mild re-IgAN with mesangial proliferation was diagnosed. Despite tonsillectomy, abnormal urinary findings did not resolve. The addition of SPT achieved remission. 
Table 1 Clinical profiles of the cases

\begin{tabular}{|c|c|c|c|c|c|}
\hline & Case 1 & Case 2 & Case 3 & Case 4 & Case 5 \\
\hline Gender & M & M & M & M & M \\
\hline Age at onset (years) & 10 & Approximately 28 & Approximately 15 & 20 & 12 \\
\hline $\begin{array}{l}\text { Onset to dialysis } \\
\text { (years) }\end{array}$ & 14 & Approximately 5 & Approximately 18 & 10 & 20 \\
\hline $\begin{array}{l}\text { Dialysis period } \\
\text { (years) }\end{array}$ & 8 & 5 & 2 & 3 & 3 \\
\hline \multirow[t]{3}{*}{ Immunosuppressant } & FK MMF MP & FK MF MP & $\mathrm{FK} \mathrm{MZ} \rightarrow \mathrm{MMF}$ & CyA MMF MP & FK MF MP \\
\hline & Basiliximab & Basiliximab & MP Basiliximab & Basiliximab & Basiliximab \\
\hline & & & & Ritu DFPP $\times 3$ & Ritu \\
\hline $\begin{array}{l}\text { Age at transplant } \\
\text { (years) }\end{array}$ & 32 & 38 & 35 & 33 & 35 \\
\hline ABO compatible & Compatible & Compatible & Compatible & Incompatible & Compatible \\
\hline Anti-HLA antibody & - & - & - & - & + \\
\hline $\begin{array}{l}\text { Crossmatch }(\mathrm{CDC}, \\
\text { FCXM) }\end{array}$ & - & - & - & - & - \\
\hline Recipient & Mother & Brother & Mother & Mother & Mother \\
\hline $\begin{array}{l}\text { Age at recurrence } \\
\text { (years) }\end{array}$ & 37 & 41 & 48 & 36 & 36 \\
\hline \multirow{2}{*}{$\begin{array}{l}\text { Urinary findings at } \\
\text { recurrence }\end{array}$} & Prot- & Prot- & Prot2+ & Prot1+ & Prot1+ \\
\hline & $\mathrm{RBC} 1+$ & $\mathrm{RBC} 2+$ & $\mathrm{RBC} 2+$ & $\mathrm{RBC} 2+$ & $\mathrm{RBC} 1+$ \\
\hline $\begin{array}{l}\mathrm{SCr}(\mathrm{mg} / \mathrm{dl}) \text { at } \\
\text { recurrence }\end{array}$ & 1.48 & 1 & 1.46 & 1.18 & 1.44 \\
\hline $\begin{array}{l}\text { Age at } \\
\text { tonsillectomy } \\
\text { (years) }\end{array}$ & 37 & 43 & 50 & 36 & 36 \\
\hline $\begin{array}{l}\text { Courses of steroid } \\
\text { pulse }\end{array}$ & $\begin{array}{l}\mathrm{mPSL} 500 \mathrm{mg} / \text { day } \\
\text { for } 3 \text { days } 1 \\
\text { course }\end{array}$ & $\begin{array}{l}\mathrm{mPSL} 500 \mathrm{mg} / \text { day } \\
\text { for } 3 \text { days } 2 \\
\text { courses }\end{array}$ & $\begin{array}{l}\text { mPSL500 mg/day for } 3 \text { days } 3 \\
\text { courses }\end{array}$ & $\begin{array}{l}\mathrm{mPSL} 500 \mathrm{mg} / \text { day } \\
\text { for } 2 \text { days } 1 \\
\text { course }\end{array}$ & $\begin{array}{l}\text { mPSL500 mg/day } \\
\text { for } 3 \text { days } 1 \text { course }\end{array}$ \\
\hline \multirow{2}{*}{$\begin{array}{l}\text { Latent urinary } \\
\text { findings }\end{array}$} & Prot- & Prot- & Prot- & Prot- & Prot- \\
\hline & $\mathrm{RBC} \pm$ & $\mathrm{RBC}-$ & $\mathrm{RBC}-$ & $\mathrm{RBC} 1+$ & $\mathrm{RBC}-$ \\
\hline Latent SCr (mg/dl) & 1.62 & 0.96 & 1.58 & 1.18 & 1.8 \\
\hline $\begin{array}{l}\text { Renal pathology at } \\
\text { IgAN diagnosis }\end{array}$ & $* \mathrm{H}$-grade I A/C & $\mathrm{H}$-grade I A/C & $\begin{array}{l}\text { Focal proliferative } \\
\text { glomerulonephritis with } \\
\text { crescents, H-grade II A/C }\end{array}$ & $\begin{array}{l}\text { H-grade I A/C, IF/ } \\
\text { TA moderate }\end{array}$ & $\begin{array}{l}\text { H-grade II } \mathrm{A} / \mathrm{C}, \\
\text { chronic active } \mathrm{T} \\
\text { cell mediated } \\
\text { rejection }\end{array}$ \\
\hline
\end{tabular}

$C D C$ complement-dependent cytotoxicity, FCXM flow cytometry crossmatch, Tac tacrolimus, CyA cyclosporin $M M F$ mycophenolate mofetil, $M Z$ mizoribine, Ritu rituximab, MP methylprednisolone, $m P S L$ methylprednisolone, DFPP double filtration plasmapheresis

* Histological grade based on "IgA nephropathy practice guideline, third edition" [13]

\section{Case 2}

The patient was performed ABO-compatible $\mathrm{KT}$ at 38 years of age. The 0 -h biopsy specimen revealed little IgA deposition without $\mathrm{C} 3$ deposition nor active lesion. It remained by the 2 -week biopsy specimen, but it then decreased and urinary findings were normal. Hematuria developed in the third-year and the fifth-year biopsy revealed re-IgAN with $\mathrm{C} 3$ deposition and mild proliferative change. The patient underwent tonsillectomy and SPT but hematuria persisted. Two months later, SPT was administered a second time and remission resulted. The seventh-year biopsy showed no active lesion.

Case 3

The patient was performed ABO-compatible $\mathrm{KT}$ at 35 years of age. Insulin therapy was initiated because of steroidal diabetes. Proteinuria developed in the 13th year, and immunosuppressive drugs were switched. But proteinuria worsened and hematuria developed. Biopsy revealed high-activity re-IgAN with cellular crescents and 
Fig. 1 Clinical course and pathological changes at re- $\operatorname{IgAN}$ diagnosis in case 3 : proteinuria and hematuria developed and the 14th-year biopsy revealed high-activity re-IgAN with crescentic lesions (b). After 1 year of tonsillectomy and SPT, he achieved clinical remission (a)
A
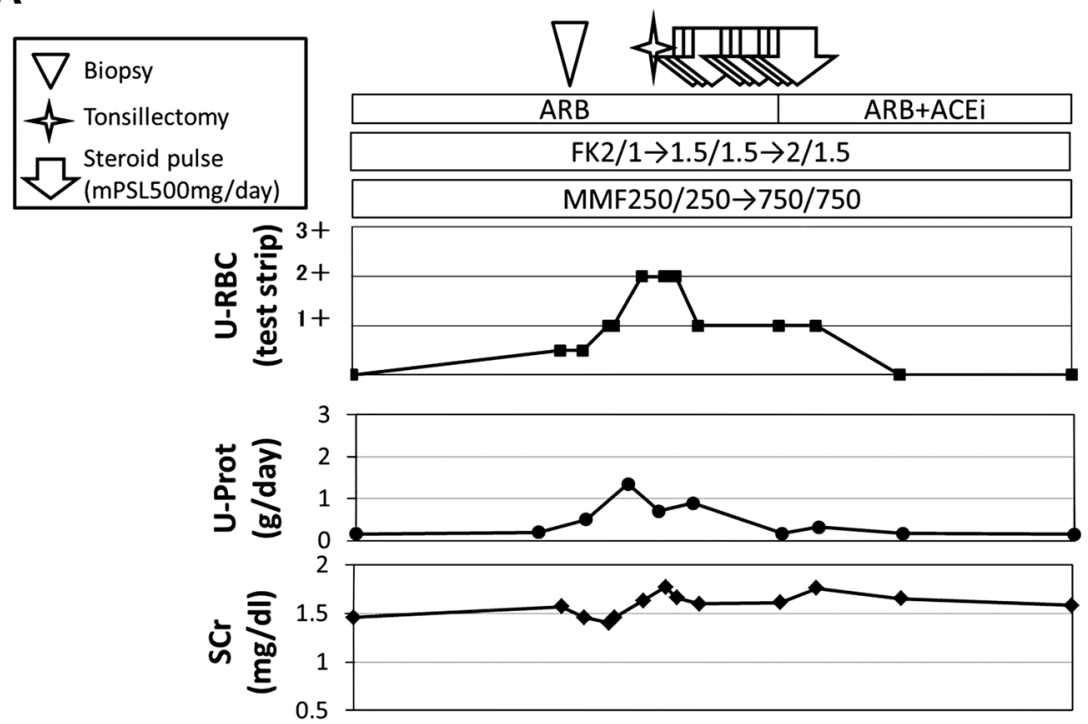

Post transplantation (years after)

$13 \quad 14$

15

16

17 18

B
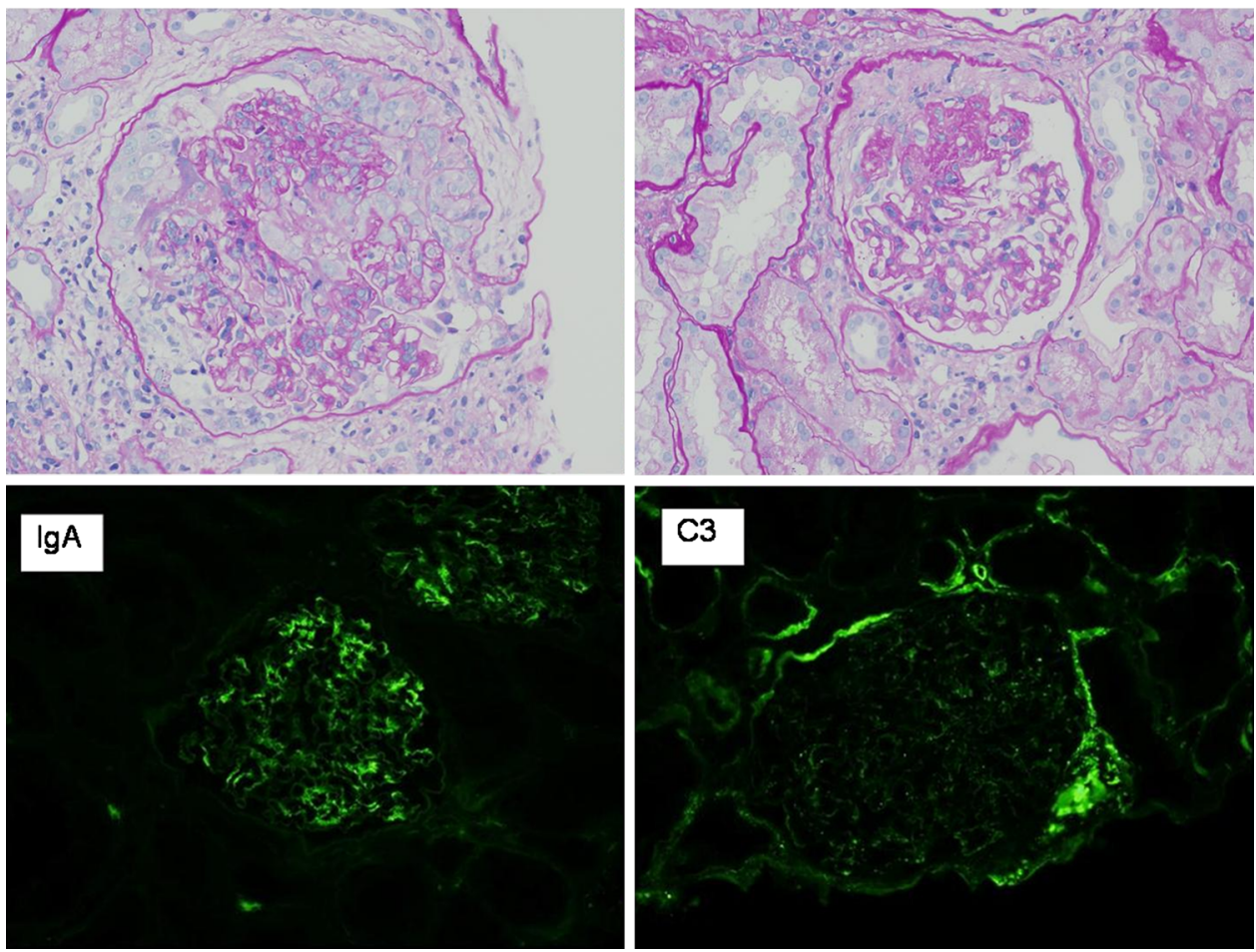

fibrocellular crescentic lesions (Fig. 1). After tonsillectomy and SPT, remission was achieved. The insulin dose was increased only during SPT.

\section{Case 4}

The patient was performed $\mathrm{ABO}$-incompatible KT at 33 years of age. Two years later, hematuria ( $2+$ to $3+)$ developed. Despite increasing the oral steroids and performing tonsillectomy, hematuria failed to improve and proteinuria developed. Biopsy revealed re-IgAN and clearly demarcated inflammatory cell infusion of medullary rays. After SPT, proteinuria resolved and hematuria improved (1+).

\section{Case 5}

The patient was performed ABO-compatible $\mathrm{KT}$ at 35 years of age. The 0-h biopsy showed normal findings. 
Proteinuria and hematuria developed 6 months later, and the first-year biopsy revealed mesangial-area expansion and IgA with C3 deposition. After tonsillectomy, proteinuria and hematuria disappeared and $\operatorname{IgA}$ deposition improved. In the third year, hematuria developed again and serum creatinine ( $\mathrm{SCr}$ ) worsened. Biopsy showed renewed IgA deposition with T cell-mediated rejection. After SPT, $\mathrm{SCr}$ and IgA deposition improved and rejection resolved following biopsy 2 months later. The fourth-year biopsy showed no active lesions.

\section{Discussion}

We performed tonsillectomy and SPT in five cases of reIgAN; all of them showed a good result, without side effects. Cases 1 and 2 showed mild activity. Both cases showed IgA deposition at the 0-h biopsy, but this decreased at the next biopsy. Generally, transmitted IgA deposition from the donor disappears within 3 years; their re-IgA were not derived from the donor. Tonsillectomy alone failed to achieve remission; adding one course of SPT in case 1 and two courses in case 2 resulted in a remission. Severe activity in case 3 achieved remission after tonsillectomy and 3 courses of SPT. Both re-IgAN and lymphocytic infusion were observed in case 4 , but a clearly demarcated area of infiltration may have represented tubulointerstitial disorder due to urinary stasis. In case 5 , chronic rejection caused $\mathrm{SCr}$ to increase. However, since tubulointerstitial disorders and rejection are not associated with hematuria, it occurs by re-IgAN. Tonsillectomy and SPT improved clinical findings in both cases, as steroids are expected to improve all of these disorders.

re- $\operatorname{IgAN}$ is diagnosed by biopsy in $25-60 \%$ of $\mathrm{KT}$ recipients with a history of primary $\operatorname{IgAN}(p-\operatorname{IgAN})$ [1-4]. Of these, graft failure develops in 18.7-26.5\% and graft loss occurs in 1.3-10\% 10 years later $[3,5,6]$. re-IgAN influences long-term graft outcome $[4,7]$.

No standard treatment for re-IgAN has been established. It is concerned that SPT is over-immunosuppression in recipients. Sakai et al. [8] reported cases of re-IgAN remission by tonsillectomy alone. Kennoki et al. [9] compared tonsillectomy and control groups and reported a significant decrease in proteinuria in the tonsillectomy group 6 months later. Clayton et al. [10] reported that steroid therapy 2 years after KT decreased the risk of graft loss, and Tsuchiya et al. [11] reported two cases of re-IgAN remission by tonsillectomy and SPT.

Tonsillectomy was performed in 21 cases of re-IgAN at our hospital during the period 2008-2012. A completed remission was achieved in 12 of the 18 cases with abnormal urinary findings by tonsillectomy alone. SPT was administered in five of six latter cases and complete remission was achieved in four. These results suggest that, in some cases, remission can be achieved by tonsillectomy alone, whereas combination with SPT and tonsillectomy is required in other cases. In addition, the numbers of courses and steroid dosage required to achieve remission differs in each case. Hotta et al. [12] reported that remission rates decreased as the clinical course duration increased. If treatment is initiated early in recurrence and activity is mild, remission may be achieved by tonsillectomy alone. However, high-activity cases may require strong immunosuppressive therapy with SPT. P-IgAN occurs in youths and they undergo transplantation during youth. In our hospital, re-IgAN patients underwent transplantation at an average age of 36 years, with an approximately 5 years interval to recurrence. They needed the treatment in order to improve long-term graft survival.

There are some issues to add to the investigation. First, these five cases of re-IgAN were identified by the episode biopsy and not only IgAN findings but also other findings, such as chronic rejection and tubulointerstitial disorder. We cannot exclude the effect of these comorbidities. Further study is required for the cases of re-IgAN alone. Second, the protocol of tonsillectomy and SPT, and third the longterm outcome of these cases. Future study is necessary.

In conclusion, SPT is effective in achieving clinical remission in re-IgAN where tonsillectomy alone fails, and SPT does not increase the complication rate.

Acknowledgments We thank Prof. Tanabe and Dr. Ishida from the Department of Urology, Tokyo Women's Medical University, for their help with the data collection.

Conflict of interest All the authors have declared no competing interest.

Open Access This article is distributed under the terms of the Creative Commons Attribution License which permits any use, distribution, and reproduction in any medium, provided the original author(s) and the source are credited.

\section{References}

1. Bumgardner GL, Amend WC, Ascher NL, Vincenti FG. Singlecenter long-term results of renal transplantation for $\operatorname{IgA}$ nephropathy. Transplantation. 1998;65(8):1053-60.

2. Wang AY, Lai FM, Yu AW, Lam PK, Chow KM, Choi PC, Lui SF, Li PK. Recurrent IgA nephropathy in renal transplant allografts. Am J Kidney Dis. 2001;38(3):588-96.

3. Andresdottir MB, Hoitsma AJ, Assmann KJ, Wetzels JF. Favorable outcome of renal transplantation in patients with IgA nephropathy. Clin Nephrol. 2001;56(4):279-88.

4. Choy BY, Chan TM, Lo SK, Lo WK, Lai KN. Renal transplantation in patients with primary immunoglobulin A nephropathy. Nephrol Dial Transplant. 2003;18(11):2399-404.

5. Andresdottir MB, Haasnoot GW, Doxiadis II, Persijn GG, Claas FH. Exclusive characteristics of graft survival and risk factors in 
recipients with immunoglobulin A nephropathy: a retrospective analysis of registry data. Transplantation. 2005;80(8):1012-8.

6. Briganti EM, Russ GR, McNeil JJ, Atkins RC, Chadban SJ. Risk of renal allograft loss from recurrent glomerulonephritis. N Engl J Med. 2002;347(2):103-9.

7. Ponticelli C, Traversi L, Feliciani A, Cesana BM, Banfi G, Tarantino A. Kidney transplantation in patients with IgA mesangial glomerulonephritis. Kidney Int. 2001;60(5):1948-54.

8. Sakai K, Saneshige M, Takasu J, Yanagisawa T, Aoki Y, Kawamura T, Mizuiri S, Aikawa A. Clinical remission and pathological progression after tonsillectomy in a renal transplant patient with recurrent IgA nephropathy. Clin Transplant. 2009;23(Suppl 20):44-8.

9. Kennoki T, Ishida H, Yamaguchi Y, Tanabe K. Proteinuriareducing effects of tonsillectomy alone in $\operatorname{IgA}$ nephropathy recurring after kidney transplantation. Transplantation. 2009; 88(7):935-41.

10. Clayton P, McDonald S, Chadban S. Steroids and recurrent IgA nephropathy after kidney transplantation. Am J Transplant. 2011;11(8):1645-9.

11. Tsuchiya T, Ito S, Yamaguchi Y, Moriyama Y, Ehara H, Deguchi T. Tonsillectomy and steroid pulse therapy for recurrent $\operatorname{IgA}$ nephropathy in renal allograft. Clin Nephrol. 2010;73(1):68-71.

12. Hotta O, Miyazaki M, Furuta T, Tomioka S, Chiba S, Horigome I, Abe K, Taguma Y. Tonsillectomy and steroid pulse therapy significantly impact on clinical remission in patients with IgA nephropathy. Am J Kidney Dis. 2001;38(4):736-43.

13. Kawamura T, Joh K, Utsunomiya Y, et al. IgA nephropathy practice guideline, third edition. Nihon Jinzo Gakkai Shi. 2011; 53(2):123-35. 